\title{
Ixekizumab improves sleep and work productivity in patients with non- radiographic axial spondyloarthritis: results from the COAST- $X$ trial at 52 weeks
}

\author{
Atul Deodhar ${ }^{1 *}$, Philip Mease ${ }^{2}$, Helena Marzo-Ortega ${ }^{3}$, Theresa Hunter ${ }^{4}$, David Sandoval ${ }^{4}$, Andris Kronbergs ${ }^{4}$,
} Steven Lauzon ${ }^{4}$, Ann Leung ${ }^{5}$ and Victoria Navarro-Compán ${ }^{6}$

\begin{abstract}
Background: Patients with non-radiographic axial spondyloarthritis experience negative impacts on sleep, work productivity, and activity impairment. Ixekizumab, a monoclonal antibody selectively targeting interleukin-17A, has shown efficacy in treating the signs and symptoms of non-radiographic axial spondyloarthritis. This analysis evaluated the effect of ixekizumab treatment on sleep, work productivity, and activity impairment in patients with non-radiographic axial spondyloarthritis.

Methods: COAST-X (NCT02757352) was a 52-week, phase 3, multicenter, randomised placebo-controlled trial evaluating 80-mg ixekizumab every 2 weeks and every 4 weeks in patients with active non-radiographic axial spondyloarthritis. Sleep disturbance was measured with the Jenkins Sleep Evaluation Questionnaire (JSEQ) and analysed using mixed-effects models for repeated measures. Work productivity and activity impairment were measured using the Work Productivity and Activity Impairment Questionnaire for Spondyloarthritis and analysed using analysis of covariance. Absenteeism, presenteeism, and overall work impairment were assessed for patients reporting paid work; activity impairment was assessed regardless of work status.

Results: Overall, patients treated with both dosing regimens of ixekizumab reported numerically greater improvements in sleep than placebo through Week 52. At Weeks 16 and 52, patients treated with ixekizumab every 4 weeks had significantly greater improvements in presenteeism ( $p=0.007$ and $p=0.003$, respectively) and overall work impairment ( $p=0.014$ and $p=0.005$, respectively) and numeric improvements in absenteeism than placebo. Patients treated with ixekizumab every 2 weeks had numerically greater improvements in absenteeism, presenteeism, and overall work impairment than placebo. Both dosing regimens of ixekizumab were associated with significantly greater improvements in activity impairment than placebo (ixekizumab every 4 weeks: $p=0.003$ at Week 16 and $p=0.004$ at Week 52; ixekizumab every 2 weeks: $p=0.007$ at Week 16 and $p=0.006$ at Week 52).
\end{abstract}

\footnotetext{
* Correspondence: deodhara@ohsu.edu

'Division of Arthritis and Rheumatic Diseases, Oregon Health \& Science University, 3181 Sam Jackson Park Rd, Portland, OR 97239, USA

Full list of author information is available at the end of the article
} 
Conclusions: Treatment with ixekizumab improved sleep, work productivity, and activity impairment in patients with nr-axSpA. Improvements in presenteeism and overall work impairment were sustained and consistent in the patients treated with ixekizumab every 4 weeks from Week 16 to Week 52. Improvements in activity impairment were sustained and consistent in both ixekizumab-treated groups from Week 16 to Week 52.

Trial registration: NCT02757352, May 2, 2016.

Keywords: Non-radiographic axial spondyloarthritis, Sleep, Work productivity, Activity impairment, Ixekizumab

\section{Background}

Non-radiographic axial spondyloarthritis (nr-axSpA), part of the axial spondyloarthritis (axSpA) disease spectrum, is classified in patients without definitive changes in the sacroiliac joints as established by the modified New York (mNY) criteria [1-3]. Patients with $n r-a x S p A$ lack definite sacroiliitis on plain radiographs but could show inflammatory changes of the sacroiliac joints on magnetic resonance imaging (MRI) [4]. Alternatively, patients with $\mathrm{nr}$-axSpA can also be classified based on HLA B-27 positivity and two additional spondyloarthritis features [4]. Nr-axSpA and radiographic axSpA ( $r$-axSpA), traditionally known as ankylosing spondylitis (AS), are different axSpA disease states sharing similar, significant disease burdens as measured by patient-reported outcomes (PROs) [1-3, 5].

AxSpA negatively affects patients' ability to sleep and work. Sleep and fatigue are considered important aspects of health for patients with axSpA, and poor sleep contributes to fatigue [6-8]. Fatigue, in turn, is associated with work productivity and activity impairment [9]. Patients with axSpA who report employment are likely to encounter increased absences away from work, decreased productivity while at work, and/or early retirement [10-12]. In addition, loss of employment is associated with worse PROs [12]. Patients' reduced ability to work from the burden of axSpA can result in significant impacts on society and the economy as axSpA is usually diagnosed at a relatively young age [10].

Many patients with axSpA who receive treatment still experience disease-related burdens in different aspects of health-related quality of life (HRQoL), which include sleep, work productivity, and activity impairment [10]. While tumor necrosis factor inhibitors (TNFi) have been found to improve axSpA patients' HRQoL, not all patients receiving TNFi tolerate or respond to treatment, suggesting that treatments with different mechanisms of action may be indicated in some patients $[4,10,13]$. Ixekizumab is a high-affinity monoclonal antibody that selectively targets interleukin-17A. COAST-X was the pivotal randomised phase 3 trial that proved the efficacy of ixekizumab for treating $\mathrm{nr}$-axSpA with objective signs of inflammation [1]. The present analysis used data from COAST-X to assess the effect of ixekizumab treatment for 52 weeks on sleep, work productivity, and activity impairment in patients with active nr-axSpA.

\section{Methods}

\section{Study design}

Details on the design of the COAST-X trial ( NCT02757352) have been published previously [1] COAST-X was a phase 3, randomised, placebocontrolled trial evaluating 80-mg ixekizumab every 2 weeks $(\mathrm{Q} 2 \mathrm{~W})$ and every 4 weeks $(\mathrm{Q} 4 \mathrm{~W})$ for 52 weeks.

\section{Patients}

Patients enrolled in COAST-X were adults with a physician's diagnosis of nr-axSpA. Enrolled patients fulfilled the Assessment of SpondyloArthritis International Society (ASAS) criteria for axSpA with active disease despite at least 12 weeks of previous therapy with NSAIDs with an inadequate response to at least 2 NSAIDs or a history of intolerance to NSAIDs. Patients who had confirmed sacroiliitis on centrally read $\mathrm{x}$-rays (following $\mathrm{mNY}$ criteria) were excluded [1]. Enrollment required active disease at screening and baseline as well as objective signs of inflammation. Active disease was defined as a Bath Ankylosing Spondylitis Disease Index (BASDAI) score of at least 4 and a total back pain score of at least 4 . Objective signs of inflammation were defined as evidence of elevated C-reactive protein (CRP) greater than $5 \mathrm{mg} / \mathrm{L}$ and/or the presence of sacroiliitis (following the ASAS definition) on centrally read MRI [1]. Patients could continue stable background medications, including NSAIDs, conventional synthetic disease-modifying antirheumatic drugs (csDMARDs), corticosteroids, and analgesics, during the trial [1]. Before participating in the study, enrolled patients gave written informed consent. The COAST-X trial was conducted in accordance with the standards of the Declaration of Helsinki and Good Clinical Practice Guidelines (CPMP/ICH/135/95) [1].

\section{Randomisation and blinding}

COAST-X enrolled 303 patients. Patients were randomised 1:1:1 to receive placebo Q2W $(N=105)$, 80-mg ixekizumab Q4W $(N=96)$, or 80-mg ixekizumab Q2W $(N=102)$ by subcutaneous injection [1]. Randomisation was stratified by country and screening MRI/CRP status 
for group comparability. There were 3 MRI/CRP statuses: positive MRI and elevated CRP, positive MRI and non-elevated CRP, and negative MRI and elevated CRP. The randomised, blinded treatment period lasted from Weeks 0 to 52. Background medications could be adjusted from Weeks 16 to 44. Patients could also switch to open-label ixekizumab Q2W or subsequent TNFi treatment following the clinical judgment of investigators from Weeks 16 to 44 . No specific switch criteria were predefined. If a patient switched to open-label treatment, the patient continued to be followed for the trial's duration, and both the patient and investigator continued to be blinded to the patient's original treatment group.

\section{Outcome measures}

Sleep problems were measured by the Jenkins Sleep Evaluation Questionnaire (JSEQ). JSEQ is comprised of 4 items that are related to trouble falling asleep, waking up numerous times throughout the night, trouble remaining asleep and/or waking up too early, and waking up after a usual amount of sleep but still being affected by fatigue [8]. Patients report how many days they experience each of the above problems over the past month. Scoring uses a 6-point Likert Scale that ranges from 0 ("no days") to 5 ("22-30 days"). Total JSEQ scores range from 0 to 20. Higher scores indicate more sleep disturbance [8]. During the COAST-X trial, patients' JSEQ scores were measured at baseline (Week 0) and Weeks 8, 16, 36, and 52.

Work productivity and activity impairment was measured with the Work Productivity and Activity Impairment Questionnaire for Spondyloarthritis (WPAI-SpA). WPAI-SpA is validated in in patients with AS [14]. WPAI-SpA is comprised of 6 questions evaluating patients' experiences during the previous week. Employment status, missed hours from work due to causes related to spondyloarthritis (SpA), missed hours due to causes not related to SpA, hours actually worked, how SpA impacted work productivity while at work, and how SpA impacted activities while not at work. WPAI-SpA scores are recorded in 4 domains, which are: percentage of absenteeism, percentage of presenteeism (reduced productivity while at work), overall work impairment (combining absenteeism and presenteeism), and activity impairment (percentage of impairment in activities away from work). Absenteeism, presenteeism, and overall work impairment are recorded for patients who report part- or full-time employment (paid work). Activity impairment is recorded for all patients regardless of their employment status. Higher WPAI-SpA scores correspond to worse work productivity and activity impairment. During the COAST-X trial, WPAI-SpA scores were measured at baseline (Week 0) and at Weeks 16 and 52 .

\section{Statistical analyses}

Data were analysed from the intent-to-treat population. Ixekizumab Q4W and ixekizumab Q2W (both $80 \mathrm{mg}$ ) were compared to placebo for the duration of the blinded treatment period from Weeks 0 to 52 and before any biologic switches to ixekizumab Q2W or TNFi. Only data up to the time of switch were included in these analyses. Changes from baseline were analysed as least squares means (LSMs) with standard errors (SEs). Comparisons between changes from baseline for JSEQ scores in different treatment groups were conducted using mixed-effects models for repeated measures (MMRM). The MMRM model used to analyse JSEQ scores included treatment, geographic region, screening MRI/ CRP status, baseline value, visit, baseline value-by-visit, and treatment-by-visit interactions as fixed factors. No imputation for missing data was performed for JSEQ analyses. Comparisons between changes from baseline for WPAI-SpA scores in different treatment groups were conducted using analysis of covariance (ANCOVA). The ANCOVA model used to analyse WPAI-SpA scores included treatment, geographic region, screening MRI/ CRP status, and baseline value as factors. Modified baseline observation carried forward (mBOCF) was used to impute missing data when analysing WPAI-SpA scores. All analyses were conducted with SAS 9.4. SAS was used to generate residual plots to confirm normality of residuals.

\section{Results}

\section{Baseline characteristics}

A total of 303 patients were enrolled in the COAST-X trial. Baseline characteristics were similar among the different treatment groups and are detailed in Table 1.

Patients' mean age was 40.3 years (SD 12.9). The mean duration of nr-axSpA symptoms was 10.7 years (SD 9.7). At baseline (Week 0), 196 patients (64.7\%) reported part- or full-time employment.

\section{Changes from baseline in sleep}

Overall, patients treated with ixekizumab Q4W and Q2W had numerically greater improvements in total JSEQ scores compared to placebo (Fig. 1).

At Week 36, patients treated with ixekizumab Q4W and Q2W had significantly greater improvements in JSEQ scores compared to placebo $(p=0.015$ and $p=$ 0.002 for ixekizumab Q4W and Q2W, respectively, versus placebo) (Fig. 1). Numeric improvements in JSEQ in the ixekizumab treatment groups were sustained and consistent to Week 52 (Fig. 1).

\section{Changes from baseline in absenteeism, presenteeism, and overall work impairment}

Patients reporting part- or full-time employment were assessed for WPAI-SpA absenteeism, presenteeism, and 
Table 1 Baseline characteristics of patients enrolled in COAST-X

\begin{tabular}{|c|c|c|c|c|}
\hline & $\begin{array}{l}\text { PBO } \\
(\mathrm{N}=105)\end{array}$ & $\begin{array}{l}\text { IXE Q4W } \\
(N=96)\end{array}$ & $\begin{array}{l}\text { IXE Q2W } \\
(N=102)\end{array}$ & $\begin{array}{l}\text { Total } \\
(N=303)\end{array}$ \\
\hline Age, years & $39.9(12.4)$ & $40.9(14.5)$ & $40.0(12.0)$ & $40.3(12.9)$ \\
\hline Male, n (\%) & $44(41.9)$ & $50(52.1)$ & $49(48.0)$ & $143(47.2)$ \\
\hline Weight, kg & $75.8(18.4)$ & $79.5(16.5)$ & $77.3(16.6)$ & $77.5(17.2)$ \\
\hline Duration of nr-axSpA symptoms, years & $10.1(8.3)$ & $11.3(10.7)$ & $10.6(10.1)$ & $10.7(9.7)$ \\
\hline Time since nr-axSpA diagnosis, years & $3.1(4.5)$ & $4.2(5.5)$ & $3.4(4.6)$ & $3.6(4.9)$ \\
\hline CRP, mg/L & $14.3(24.4)$ & $12.4(18.0)$ & $12.1(17.8)$ & $12.9(20.4)$ \\
\hline \multicolumn{5}{|l|}{ Screening MRI/CRP status, n (\%) } \\
\hline Positive MRI and elevated CRP & $38(36.2)$ & $30(31.3)$ & $39(38.2)$ & $107(35.3)$ \\
\hline Positive MRI and nonelevated CRP & $40(38.1)$ & $36(37.5)$ & $34(33.3)$ & $110(36.3)$ \\
\hline Negative MRI and elevated CRP & $26(24.8)$ & $30(31.3)$ & $28(27.5)$ & $84(27.7)$ \\
\hline \multicolumn{5}{|l|}{ Therapy, n (\%) } \\
\hline Current csDMARD use, including MTX & $36(34.3)$ & $40(41.7)$ & $42(41.2)$ & $118(38.9)$ \\
\hline Current MTX use & $17(16.2)$ & $17(17.7)$ & $15(14.7)$ & $49(16.2)$ \\
\hline Current NSAID/COX-2 inhibitor use & $96(91.4)$ & $81(84.4)$ & $95(93.1)$ & $272(89.8)$ \\
\hline ASDAS-CRP & $3.8(0.9)$ & $3.8(0.8)$ & $3.9(0.8)$ & $3.8(0.8)$ \\
\hline BASDAI & $7.2(1.5)$ & $7.0(1.5)$ & $7.3(1.3)$ & $7.2(1.4)$ \\
\hline Sleep (JSEQ) & $9.4(5.6)$ & $9.4(5.3)$ & $10.4(5.3)$ & $9.7(5.4)$ \\
\hline Reported part- or full-time work, n (\%) & $69(65.7)$ & $61(63.5)$ & $66(64.7)$ & $196(64.7)$ \\
\hline \multicolumn{5}{|l|}{ Work productivity (WPAI-SpA) } \\
\hline Absenteeism & $15.6(26.8)^{\mathrm{a}}$ & $12.1(27.0)^{b}$ & $16.1(26.5)^{c}$ & $14.7(26.7)^{\mathrm{c}}$ \\
\hline Presenteeism* & $62.1(18.7)^{\mathrm{e}}$ & $50.2(22.3)^{f}$ & $56.3(24.8)^{9}$ & $56.7(22.4)^{h}$ \\
\hline Overall work impairment* & $65.6(20.2)^{e}$ & $51.9(22.8)^{f}$ & $59.3(26.4)^{9}$ & $59.5(23.7)^{\natural}$ \\
\hline Activity impairment & $66.4(20.4)$ & $63.3(21.5)$ & $66.1(20.7)$ & $65.3(20.8)$ \\
\hline \multicolumn{5}{|c|}{$\begin{array}{l}{ }^{\mathrm{a}} \mathrm{N}=65 ;{ }^{\mathrm{b}} \mathrm{N}=53 ;{ }^{\mathrm{c}} \mathrm{N}=60 ;{ }^{\mathrm{d}} \mathrm{N}=178 ;{ }^{\mathrm{e}} \mathrm{N}=62 ;{ }^{\mathrm{f}} \mathrm{N}=49 ;{ }^{9} \mathrm{~N}=57 ;{ }^{\mathrm{h}} \mathrm{N}=168 \\
\text { Data are mean (SD) unless otherwise stated } \\
P \text { values from Fisher's exact test for categorical data (Monte Carlo estimate of exact } p \text {-value was used for categorical values that have more than } 2 \text { categories) and } \\
\text { analysis of variance with treatment as a factor for continuous data. }{ }^{*} p<0.05 \\
\text { ASDAS-CRP Ankylosing Spondylitis Disease Activity Score with C-Reactive Protein; BASDAI Bath Ankylosing Spondylitis Disease Activity Index; } \\
C S D M A R D \text { Conventional synthetic disease-modifying antirheumatic drug;COX-2 Cyclooxygenase-2; CRP C-reactive protein; IXE Q2W } 80 \text {-mg ixekizumab every } \\
2 \text { weeks; IXE Q4W 80-mg ixekizumab every } 4 \text { weeks; JSEQ Jenkins Sleep Evaluation Questionnaire; MRI Magnetic resonance imaging; MTX Methotrexate; } \\
n \text { number of patients in a subcategory; N Number of patients in the analysis category; NRS Numeric rating score; nr-axSpA nonradiographic axial } \\
\text { spondyloarthritis; PBO Placebo; PtGA Patient's Global Assessment of Disease Activity; SD Standard deviation; WPAl-SpA Work Productivity and Activity } \\
\text { Impairment Questionnaire for Ankylosing Spondylitis }\end{array}$} \\
\hline
\end{tabular}

overall work impairment. Patients treated with both ixekizumab dosing regimens experienced numerically greater improvements from baseline in absenteeism, presenteeism, and overall work impairment at Weeks 16 and 52 compared to placebo (Fig. 2).

The differences in changes from baseline in presenteeism and overall work impairment were significant for patients treated with ixekizumab Q4W versus placebo at Weeks 16 and 52. For presenteeism, the LSM difference between ixekizumab Q4W and placebo was - 12.7 (SE 4.6; $p=0.007$ ) at Week 16, and the LSM difference was -13.6 (SE 4.6; $p=0.003$ ) at Week 52. For overall work impairment, the LSM difference between ixekizumab Q4W and placebo was - 12.3 (SE
$4.9)$ at Week $16(p=0.014)$, and the LSM difference was $-13.8(\mathrm{SE} 4.8)$ at Week $52(p=0.005)$.

\section{Changes from baseline in activity impairment}

Activity impairment was assessed regardless of employment status. Patients treated with both ixekizumab dosing regimens experienced significantly greater improvements in activity impairment at Weeks 16 and 52 compared to placebo (Fig. 2). At Week 16, the LSM difference between ixekizumab Q4W and placebo was 10.4 (SE 3.4; $p=0.003$ ), and the LSM difference between ixekizumab Q2W and placebo was - 9.1 (SE 3.4; $p=$ 0.007). At Week 52, the LSM difference between ixekizumab Q4W and placebo was - 10.6 (SE 3.7; $p=0.004$ ), 


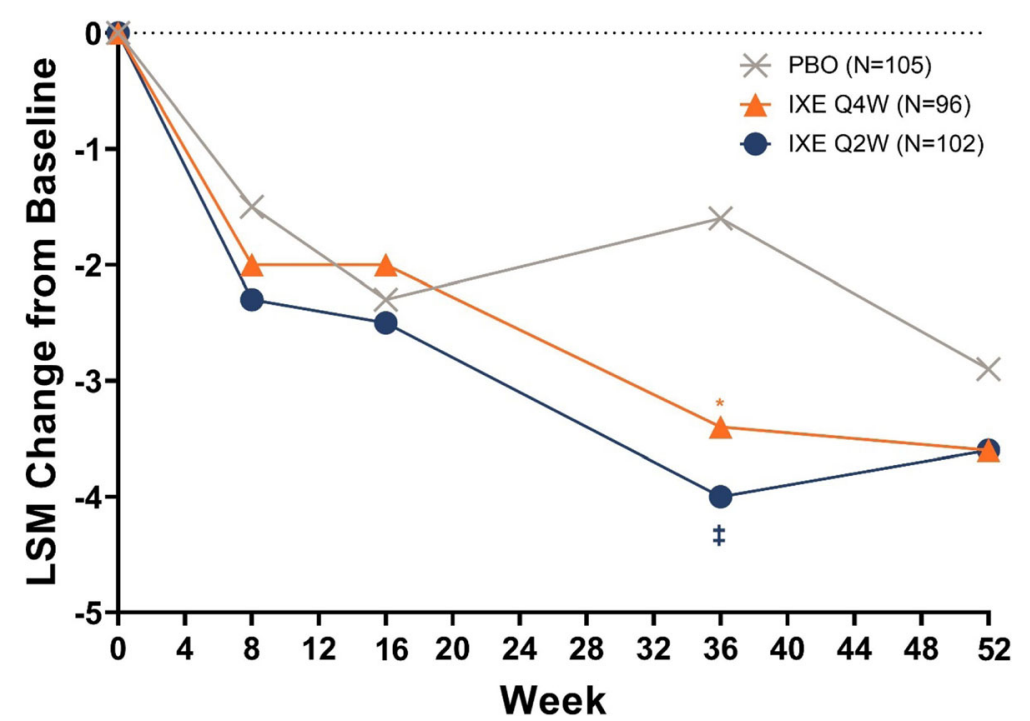

Fig. 1 Changes from baseline in sleep as measured by the Jenkins Sleep Evaluation Questionnaire Values are LSM from MMRM. Week 8: PBO, $N x=101 ;$ IXE Q4W, Nx=95; IXE Q2W, Nx=101. Week 16: PBO, Nx=99; IXE Q4W, Nx=96; IXE Q2W, Nx=98. Week 36: PBO, Nx=39; IXE Q4W, $N x=56 ;$ IXE Q2W, $N x=58$. Week 52: PBO, $N x=34 ;$ IXE Q4W, $N x=53$; IXE Q2W, Nx= 52. P values were from MMRM (treatment vs. placebo). ${ }^{*}=p<0.05, \neq=p<0.01, \dagger=p<0.001$. IXE Q2W = 80-mg ixekizumab every 2 weeks; IXE Q4W = 80-mg ixekizumab every 4 weeks; IXE Q4W = 80-mg ixekizumab every 2 weeks; $L S M=$ least squares mean; MMRM = mixed-effect model repeated measure; $N=$ number of patients in the treatment group; $\mathrm{Nx}=$ number of patients with non-missing values; $\mathrm{PBO}=$ placebo

and the LSM difference between ixekizumab Q2W and placebo was - 10.0 (SE 3.6; $p=0.006)$.

\section{Discussion}

In this study, patients with $\mathrm{nr}$-axSpA treated with ixekizumab reported improved sleep, work productivity, and activity impairment. Primary results of the COAST-X trial have established the efficacy of ixekizumab in treating the signs of symptoms of $\mathrm{nr}-\mathrm{axSpA}$ as demonstrated by significant improvements in ASAS40 response as early as Week 1 [1].

Patients with nr-axSpA are more likely to report poor sleep than the general population, and patients with nraxSpA have reported worse sleep disturbance at baseline compared to patients with r-axSpA [15-17]. The baseline mean JSEQ score for patients naïve to biologic disease-modifying antirheumatic drugs (bDMARDs) with nr-axSpA enrolled in the COAST-X trial was slightly higher than the scores for bDMARD-naïve patients with $r$-axSpA enrolled in the COAST-V trial, which may suggest worse sleep disturbance in bDMARD-naïve patients with nr-axSpA $[1,18]$. However, TNFi-experienced patients with $\mathrm{r}$-axSpA enrolled in COAST-W reported higher baseline JSEQ scores than bDMARD-naive patients enrolled in COAST-X and COAST-V [18]. Factors contributing to the observation of greater sleep disturbance in $\mathrm{nr}$-axSpA compared to $\mathrm{r}$-axSpA may include a greater proportion of women being affected by $\mathrm{nr}$-axSpA as well as a greater prevalence of diagnosed fibromyalgia in $\mathrm{nr}$-axSpA patients [19]. Central sensitization, which is more common in female patients with axSpA and in patients with fibromyalgia, can also contribute to sleep disturbance [20]. Sleep disruption due to disease activity has also been tied to work impairment $[15,21]$. Because sleep disruptions may exacerbate chronic inflammatory conditions or serve a marker of underlying inflammation, sleep quality could serve as a proxy for disease activity [15].

While there is not yet a full understanding of nraxSpA's impact on work disability and economic consequences, nr-axSpA's effects are estimated to be equivalent to those of $\mathrm{r}$-axSpA because both disease states share similar severity in disease activity, pain, and fatigue $[11,16]$. Baseline absenteeism, overall work impairment, and activity impairment scores were slightly higher in bDMARD-naïve patients with nr-axSpA enrolled in the COAST-X trial compared to the bDMARD-naïve patients with $r$-axSpA enrolled in the COAST-V trial [22]. TNFi-experienced patients with $\mathrm{r}$-axSpA enrolled in COAST-W reported higher baseline WPAI-SpA scores across all domains than bDMARD-naïve patients enrolled in COAST-X and COAST-V [22]. As described above, central sensitization can affect work impairment because it can worsen sleep disruption [19, 20].

Maintaining employment is an important factor in patients' quality of life, influencing additional psychosocial, societal, and financial impacts [14, 23, 24]. In a 2015 study evaluating the baseline burden of early nraxSpA and the effect of treatment with etanercept, $69.7 \%(129 / 185)$ of patients were employed at 


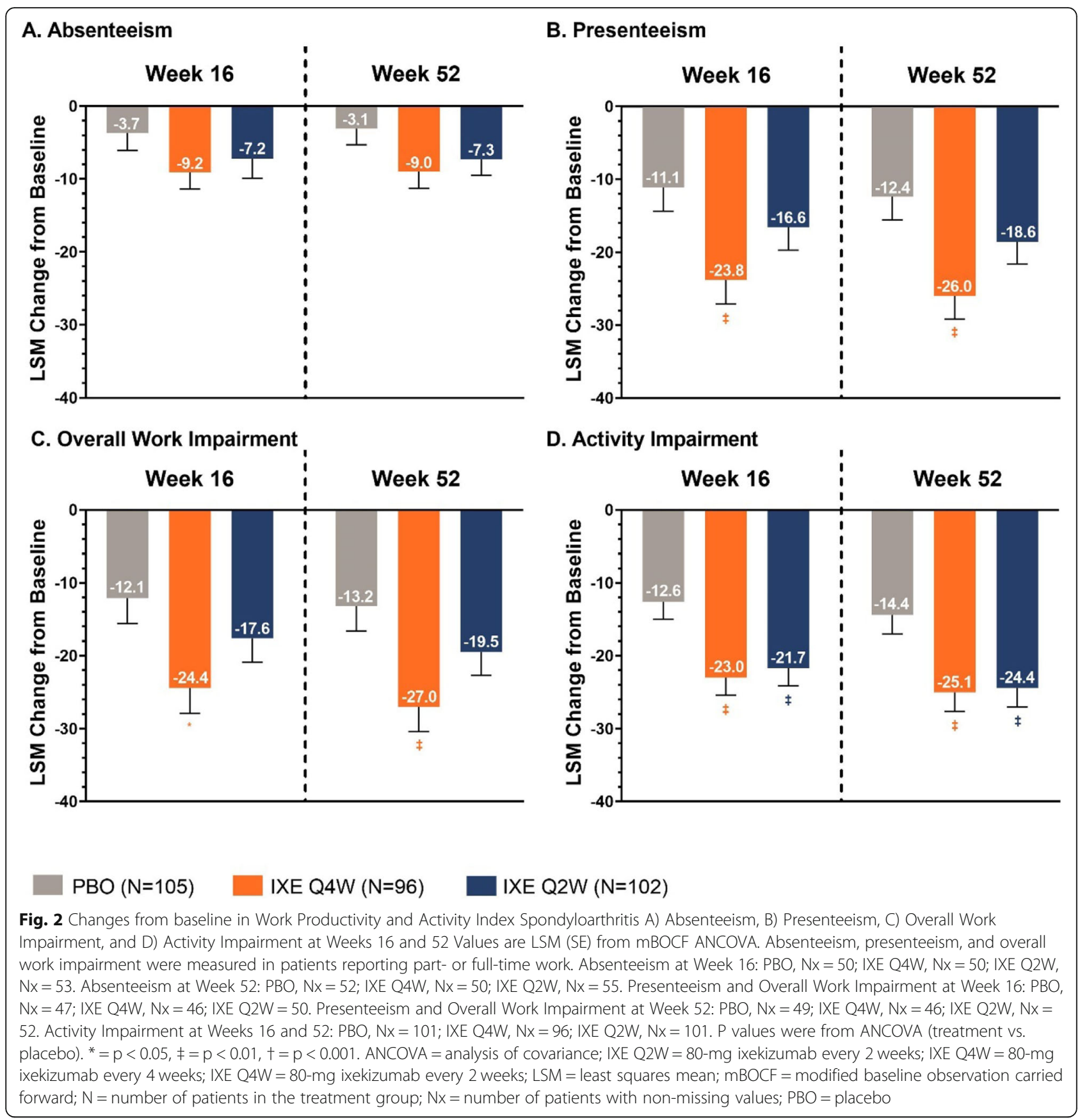

baseline; a similar proportion was found in the present analysis with $64.7 \%(196 / 303)$ of patients enrolled in COAST-X reporting part- or full-time employment [16]. European patients with nr-axSpA had greater work productivity loss compared with the general population, and bDMARD-naïve patients reported worse presenteeism, overall work impairment, and activity impairment than bDMARD-experienced patients [25].

Fatigue and sleep are inherently linked, and patients with axSpA consider both important for overall health
[6]. Results from a study of patients with AS and rheumatoid arthritis (RA) treated with etanercept showed a significant association between fatigue and presenteeism and activity impairment (but not overall work impairment or absenteeism) in patients with AS as well as an association between fatigue and all WPAISpA domains in patients with RA [9]. A study of patients with axSpA in the United Kingdom found an association between absenteeism and worse fatigue, which was more likely in those with nr-axSpA; presenteeism, work impairment, and activity impairment were also associated 
with higher levels of fatigue [26]. In another study using data from the British Society for Rheumatology Biologics Register, fatigue was associated with absenteeism and presenteeism in patients with axSpA [21]. Results from the European Map of Axial Spondyloarthritis survey suggested that worse patient-reported outcomes, particularly greater disease activity and psychological distress, were associated with work-related issues [27].

In a recent study using data from 2 trials of patients with $r$-axSpA naive to bDMARDs and those who were intolerant of or who had inadequate response to TNFi (COAST-V and COAST-W, respectively), treatment with ixekizumab improved work productivity and activity impairment as measured by WPAI-SpA with sustained and consistent results through Week 52 [22]. In the context of $\mathrm{nr}$-axSpA, the efficacy of ixekizumab treatment in improving signs and symptoms in the COAST-X trial has been demonstrated [1]. A recent study using COAST-X trial data demonstrated that treatment with ixekizumab improved patient-reported outcomes in $\mathrm{nr}$-axSpA, including patient global disease activity, spinal pain, function, stiffness, fatigue, and spinal pain at night [13]. An additional recent study using COAST-X trial data showed that treatment with ixekizumab improved patient-reported functioning and health in nr-axSpA [28]. Overall, these data suggest that ixekizumab has significant efficacy on patient-reported outcomes across the axSpA disease spectrum. Beyond axSpA, ixekizumab has also shown effectiveness in improving work productivity in patients with moderate-tosevere plaque psoriasis and psoriatic arthritis [29-31].

The results of this study show improvements in sleep, work productivity, and activity impairment and are consistent with previously reported results demonstrating the efficacy of ixekizumab in treating $\mathrm{nr}$-axSpA $[1,13]$. Collectively, these results suggest treatment with ixekizumab can improve patient-reported outcomes as well as overall HRQoL in the specific context of nr-axSpA.

Limitations of this study include the absence of specific predefined criteria to switch to open label, which followed regulatory requirements. At investigator discretion, substantial proportions of patients who achieved clinical response were switched from their blinded ixekizumab treatment to open-label ixekizumab and were considered non-responders. In addition, while over $60 \%$ of patients enrolled in COAST-X reported paid work, WPAI-SpA requires part- or full-time employment for absenteeism, presenteeism, and overall work impairment scores. The limited number of patients reporting paid work may have impacted analyses determining the statistical significance of changes from baseline in WPAI-SpA scores, particularly in absenteeism.

Strengths of the COAST-X trial included the enrollment of patients from multiple global regions. In addition, enrolled patients had objective signs of inflammation confirmed by screening MRI/CRP status. Patients enrolled in COAST-X also experienced disease symptoms that lasted over 10 years without transition to $\mathrm{r}$-axSpA. This analysis used scores from the validated instruments JSEQ and WPAI-SpA. The presence and consistency of a placebo arm through Week 52 allowed for a true comparison of the effects of ixekizumab against placebo on sleep, work productivity, and activity impairment. COAST-X met ethical requirements by allowing patients to modify background therapy or switch to open-label ixekizumab Q2W after Week 16 (at investigator discretion).

\section{Conclusions}

Patients with active nr-axSpA treated with ixekizumab reported improvements in sleep disturbance, work productivity, and activity impairment compared to those receiving placebo. Numeric improvements in sleep were observed from Weeks 8 to 52 . Significant improvements in presenteeism and overall work impairment were sustained and consistent in patients treated with ixekizumab Q4W from Week 16 to Week 52, and significant improvements in activity impairment were sustained and consistent in patients treated with ixekizumab Q4W and Q2W from Week 16 to Week 52.

\section{Abbreviations}

ANCOVA: analysis of covariance; AS: ankylosing spondylitis;

ASAS: Assessment of SpondyloArthritis International Society; axSpA: axial spondyloarthritis; BASDAl: Bath Ankylosing Spondylitis Disease Activity Index; bDMARD: biologic disease-modifying antirheumatic drug; CRP: C-reactive protein; csDMARD: conventional synthetic disease-modifying antirheumatic drug; HRQoL: health-related quality of life; JSEQ: Jenkins Sleep Evaluation Questionnaire; LSM: least squares mean; MMRM: mixed-effects model for repeated measures; mNY: modified New York; MRI: magnetic resonance imaging; nr-axSpA: non-radiographic axial spondyloarthritis; NSAID: nonsteroidal anti-inflammatory drug; PRO: patient-reported outcome:

Q2W: every 2 weeks; Q4W: every 4 weeks; RA: rheumatoid arthritis; raxSpA: radiographic axial spondyloarthritis; SE: standard error; TNFi: tumor necrosis factor inhibitors; WPAI-SpA: Work Productivity and Activity Impairment Questionnaire for Spondyloarthritis

\section{Acknowledgments}

Eli Lilly and Company provided funding for the sponsorship of this study and the publication of this manuscript. All authors had complete access to the data used in this study and take full responsibility for the integrity of the data and accuracy of the data analysis. Nicole Lipitz of Syneos Health provided writing and editorial assistance with funding provided by Eli Lilly and Company. Helena Marzo-Ortega is supported by the National Institute for Health Research (NIHR) Leeds Biomedical Research Centre (LBRC). The views expressed are those of the author and not necessarily those of the (UK) National Health Service (NHS), the NIHR, or the (UK) Department of Health.

\section{Authors' contributions}

AD contributed to the study's conception, data acquisition and interpretation, and critical revision of the manuscript. PM, HMO, and SL contributed to data interpretation and critical revision of the manuscript. TH and AK contributed to the study's conception, data interpretation, and critical revision of the manuscript. DS contributed to the study's conception and design, data interpretation, and critical revision of the manuscript. AL contributed to data analysis, data interpretation, drafting of the manuscript, and critical revision of the manuscript. VNC contributed to data analysis, data interpretation, and critical revision of the manuscript. 


\section{Funding}

The study was sponsored by Eli Lilly and Company.

\section{Availability of data and materials}

Data on all individual participant data collected during the trial (except pharmacokinetic or genetic data) are available upon request. Access is granted after approval by an independent review committee and after receiving a signed data sharing agreement. Please submit any requests for data online.

\section{Declarations}

\section{Ethics approval and consent to participate}

The COAST-X trial was conducted in accordance with the standards of the Declaration of Helsinki and Good Clinical Practice Guidelines (CPMP/ICH/135/ 95). The master ethics committee was Schulman Associates IRB, Cincinnati, $\mathrm{OH}, \mathrm{USA}$. All patients gave written informed consent before trial start.

\section{Consent for publication}

Not applicable.

\section{Competing interests}

$A D$ has received consulting fees from and has served on the advisory boards of AbbVie, Amgen, Boehringer Ingelheim, Bristol Myers Squibb, Celgene, Eli Lilly and Company, Galapagos, Glaxo Smith \& Kline, Janssen, Novartis, Pfizer, and UCB as well as receiving research grants from AbbVie, Eli Lilly, Glaxo Smith \& Kline, Novartis, Pfizer, and UCB. PM has received research grants, consulting fees, and/or speaker fees from Abbvie, Amgen, Boehringer Ingelheim, Bristol Myers Squibb, Eli Lilly and Company, Galapagos, Gilead, GlaxoSmithKline, Janssen, Novartis, Pfizer, SUN Pharma, and UCB. HMO has received grant or research support from Janssen and Novartis, has received consulting fees from AbbVie, Celgene, Janssen, Eli Lilly and Company, Novartis, Pfizer, and UCB, and has received speaker fees from AbbVie, Biogen, Celgene, Janssen, Eli Lilly and Company, Novartis, Pfizer, Takeda, and UCB. TH, DS, AK, and SL are employees and shareholders of Eli Lilly and Company. $\mathrm{AL}$ is an employee of Syneos Health, vendor of Eli Lilly and Company. Victoria Navarro-Compán has consulting fees, speaker fees, and research grants from Abbvie, Bristol Myers Squibb, Janssen, Eli Lilly and Company, MSD, Novartis, Pfizer, Roche, and UCB.

\section{Author details}

'Division of Arthritis and Rheumatic Diseases, Oregon Health \& Science University, 3181 Sam Jackson Park Rd, Portland, OR 97239, USA. ${ }^{2}$ Swedish Medical Center/Providence St. Joseph Health and University of Washington, Seattle, WA, USA. ${ }^{3}$ NIHR Leeds Biomedical Research Centre, Leeds Teaching Hospitals Trust and LIRMM, University of Leeds, West Yorkshire, Leeds, UK. ${ }^{4}$ Eli Lilly and Company, Indianapolis, IN, USA. ${ }^{5}$ Syneos Health, Morrisville, NC, USA. ${ }^{6}$ University Hospital La Paz, IdiPaz, Madrid, Spain.

\section{Received: 23 March 2021 Accepted: 25 June 2021}

\section{Published online: 25 September 2021}

\section{References}

1. Deodhar A, van der Heijde D, Gensler LS, Kim TH, Maksymowych WP, Ostergaard $M$, et al. Ixekizumab for patients with non-radiographic axial spondyloarthritis (COAST-X): a randomised, placebo-controlled trial. Lancet (London, England). 2020;395(10217):53-64

2. Lockwood MM, Gensler LS. Nonradiographic axial spondyloarthritis. Best Pract Res Clin Rheumatol. 2017;31(6):816-29. https://doi.org/10.1016/j.berh.2 018.08.008.

3. Burgos-Varga R, Wei JC, Rahman MU, Akkoc N, Haq SA, Hammoudeh M, et al. The prevalence and clinical characteristics of nonradiographic axia spondyloarthritis among patients with inflammatory back pain in rheumatology practices: a multinational, multicenter study. Arthritis research \& therapy. 2016;18(1):132. https://doi.org/10.1186/s13075-016-1027-9.

4. Robinson PC, Sengupta R, Siebert S. Non-radiographic axial Spondyloarthritis (nr-axSpA): advances in classification. Imaging and Therapy Rheumatology and therapy. 2019;6(2):165-77. https://doi.org/10.1007/s40744-019-0146-6.

5. Malaviya AN, Rawat R, Agrawal N, Patil NS. The nonradiographic axial Spondyloarthritis, the radiographic axial Spondyloarthritis, and ankylosing spondylitis: the tangled skein of rheumatology. International journal of rheumatology. 2017:2017:1824794.

6. Kiltz U, Essers I, Hiligsmann M, Braun J, Maksymowych WP, Taylor WJ, et al. Which aspects of health are most important for patients with spondyloarthritis? A Best Worst Scaling based on the ASAS Health Index. Rheumatology (Oxford, England). 2016;55(10):1771-6.

7. Garrido-Cumbrera M, Hillmann O, Mahapatra R, Trigos D, Zajc P, Weiss L, et al. Improving the Management of Psoriatic Arthritis and Axial Spondyloarthritis: roundtable discussions with healthcare professionals and patients. Rheumatology and therapy. 2017;4(2):219-31. https://doi.org/10.1 007/s40744-017-0066-2.

8. Deodhar A, Braun J, Inman RD, Mack M, Parasuraman S, Buchanan J, et al. Golimumab reduces sleep disturbance in patients with active ankylosing spondylitis: results from a randomized, placebo-controlled trial. Arthritis Care Res. 2010;62(9):1266-71. https://doi.org/10.1002/acr.20233.

9. Druce KL, Aikman L, Dilleen M, Burden A, Szczypa P, Basu N. Fatigue independently predicts different work disability dimensions in etanercepttreated rheumatoid arthritis and ankylosing spondylitis patients. Arthritis research \& therapy. 2018;20(1):96. https://doi.org/10.1186/s13075-018-1598-8.

10. Strand V, Singh JA. Patient Burden of axial Spondyloarthritis. Journal of clinical rheumatology : practical reports on rheumatic \& musculoskeletal diseases. 2017;23(7):383-91. https://doi.org/10.1097/RHU.0000000000000589.

11. Boonen A, Sieper J, van der Heijde D, Dougados M, Bukowski JF, Valluri S, et al. The burden of non-radiographic axial spondyloarthritis. Semin Arthritis Rheum. 2015;44(5):556-62. https://doi.org/10.1016/j.semarthrit.2014.10.009.

12. Martindale J, Shukla R, Goodacre J. The impact of ankylosing spondylitis/ axial spondyloarthritis on work productivity. Best Pract Res Clin Rheumatol. 2015;29(3):512-23. https://doi.org/10.1016/j.berh.2015.04.002.

13. Deodhar A, Mease PJ, Rahman P, Navarro-Compán V, Marzo-Ortega H, Hunter $T$, et al. Ixekizumab improves patient-reported outcomes in nonradiographic axial spondyloarthritis: results from the COAST-X trial. Rheumatology and therapy. 2020; In press.

14. Reilly MC, Gooch KL, Wong RL, Kupper H, van der Heijde D. Validity, reliability and responsiveness of the Work Productivity and Activity Impairment Questionnaire in ankylosing spondylitis. Rheumatology (Oxford, England). 2010;49(4):812-9.

15. Leverment S, Clarke E, Wadeley A, Sengupta R. Prevalence and factors associated with disturbed sleep in patients with ankylosing spondylitis and non-radiographic axial spondyloarthritis: a systematic review. 2017;37(2): 257-71.

16. Dougados M, Tsai WC, Saaibi DL, Bonin R, Bukowski J, Pedersen R, et al. Evaluation of health outcomes with Etanercept treatment in patients with early nonradiographic axial Spondyloarthritis. J Rheumatol. 2015;42(10): 1835-41. https://doi.org/10.3899/jrheum.141313.

17. Sieper J, Kivitz A, van Tubergen A, Deodhar A, Coteur G, Woltering F, et al Impact of Certolizumab Pegol on patient-reported outcomes in patients with axial Spondyloarthritis. Arthritis Care Res. 2015;67(10):1475-80. https:// doi.org/10.1002/acr.22594.

18. Mease P, Walsh JA, Baraliakos X, Inman R, de Vlam K, Wei JC, et al. Translating improvements with Ixekizumab in clinical trial outcomes into clinical practice: ASAS40, pain, fatigue, and sleep in ankylosing spondylitis. Rheumatology and therapy. 2019;6(3):435-50. https://doi.org/10.1007/s4 0744-019-0165-3.

19. Wallis D, Haroon N, Ayearst R, Carty A, Inman RD. Ankylosing spondylitis and nonradiographic axial spondyloarthritis: part of a common spectrum or distinct diseases? J Rheumatol. 2013;40(12):2038-41. https://doi.org/10.3899/ jrheum.130588.

20. Wright GC, Kaine J, Deodhar A. Understanding differences between men and women with axial spondyloarthritis. Semin Arthritis Rheum. 2020;50(4): 687-94. https://doi.org/10.1016/j.semarthrit.2020.05.005.

21. Macfarlane GJ, Shim J, Jones GT, Walker-Bone K, Pathan E, Dean LE. Identifying persons with axial Spondyloarthritis at risk of poor work outcome: results from the British Society for Rheumatology biologics register. J Rheumatol. 2019;46(2):145-52. https://doi.org/10.3899/jrheum.180477.

22. Marzo-Ortega H, Mease PJ, Rahman P, Navarro-Compán V, Strand V, Dougados $\mathrm{M}$, et al. Impact of Ixekizumab on work productivity in patients with ankylosing spondylitis: results from the COAST-V and COAST-W trials at 52 weeks. Rheumatology and therapy. 2020;7(4):759-74. https://doi.org/10.1 007/s40744-020-00225-4

23. Boonen A, van der Linden SM. The burden of ankylosing spondylitis. The Journal of rheumatology Supplement. 2006;78:4-11. 
24. de Hooge M, Ramonda R, Lorenzin M, Frallonardo P, Punzi L, Ortolan A, et al. Work productivity is associated with disease activity and functional ability in Italian patients with early axial spondyloarthritis: an observational study from the SPACE cohort. Arthritis research \& therapy. 2016;18(1):265. https://doi.org/10.1186/s13075-016-1162-3.

25. Sieper J, Holbrook T, Black CM, Wood R, Hu X, Kachroo S. Burden of illness associated with non-radiographic axial spondyloarthritis: a multiperspective European cross-sectional observational study. Rheumatol Int. 2016;34(6): 975-83.

26. Espahbodi S, Bassett P, Cavill C, Freeth M, Hole J, Sengupta R. Fatigue contributes to work productivity impairment in patients with axial spondyloarthritis: a cross-sectional UK study. Clin Exp Rheumatol. 2017;35(4): $571-8$.

27. Garrido-Cumbrera M, Bundy C, Navarro-Compán V, Makri S, Sanz-Gómez S, Christen L, et al. Patient-reported impact of axial Spondyloarthritis on working life: results from the EMAS survey. Arthritis Care Res. 2020. https:/ doi.org/10.1002/acr.24426.

28. Walsh JA, Magrey MN, Baraliakos X, Inui K, Weng MY, Lubrano E, et al. Ixekizumab improves functioning and health in the treatment of active non-radiographic axial Spondyloarthritis: 52-week results, COAST-X trial. Arthritis Care Res. 2020. https://doi.org/10.1002/acr.24482.

29. Armstrong AW, Lynde CW, McBride SR, Stahle M, Edson-Heredia E, Zhu B, et al. Effect of Ixekizumab treatment on work productivity for patients with moderate-to-severe plaque psoriasis: analysis of results from 3 randomized phase 3 clinical trials. JAMA dermatology. 2016;152(6):661-9. https://doi. org/10.1001/jamadermatol.2016.0269.

30. Gottlieb AB, Strand V, Kishimoto M, Mease P, Thaci D, Birt J, et al. Ixekizumab improves patient-reported outcomes up to 52 weeks in bDMARD-naive patients with active psoriatic arthritis (SPIRIT-P1) Rheumatology (Oxford, England). 2018;57(10):1777-88.

31. Kavanaugh A, Marzo-Ortega H, Vender R, Wei CC, Birt J, Adams DH, et al. Ixekizumab improves patient-reported outcomes in patients with active psoriatic arthritis and inadequate response to tumour necrosis factor inhibitors: SPIRIT-P2 results to 52 weeks. Clin Exp Rheumatol. 2019;37(4): $566-74$.

\section{Publisher's Note}

Springer Nature remains neutral with regard to jurisdictional claims in published maps and institutional affiliations.

Ready to submit your research? Choose BMC and benefit from:

- fast, convenient online submission

- thorough peer review by experienced researchers in your field

- rapid publication on acceptance

- support for research data, including large and complex data types

- gold Open Access which fosters wider collaboration and increased citations

- maximum visibility for your research: over $100 \mathrm{M}$ website views per year

At $\mathrm{BMC}$, research is always in progress.

Learn more biomedcentral.com/submissions 